\title{
BMJ Open 'I thought it would be a very clearly defined role and actually it wasn't': a qualitative study of transition training for pharmacists moving into general practice settings in Wales
}

\author{
Sophie Bartlett (1) , ${ }^{1}$ Alison Bullock, ${ }^{1}$ Kate Spittle ${ }^{2}$
}

To cite: Bartlett S, Bullock A, Spittle K. I thought it would be a very clearly defined role and actually it wasn't': a qualitative study of transition training for pharmacists moving into general practice settings in Wales. BMJ Open 2021;11:e051684. doi:10.1136/ bmjopen-2021-051684

- Prepublication history and additional supplemental material for this paper are available online. To view these files, please visit the journal online (http://dx.doi.org/10.1136/ bmjopen-2021-051684).

Received 25 March 2021 Accepted 12 October 2021

D Check for updates

(c) Author(s) (or their employer(s)) 2021. Re-use permitted under CC BY-NC. No commercial re-use. See rights and permissions. Published by BMJ.

${ }^{1}$ Cardiff Unit for Research and Evaluation in Medical and Dental Education, School of Social Sciences, Cardiff University, Cardiff, UK

${ }^{2}$ GP Pharmacist, NHS Wales Health Education and Improvement Wales, Nantgarw, UK

Correspondence to

Dr Sophie Bartlett;

bartletts2@cardiff.ac.uk

\section{ABSTRACT}

Objective Pharmacists are increasingly contributing to the skill mix of general practice surgeries to help alleviate pressures faced by UK doctors working in primary care. However, they need support in overcoming barriers to their integration. The purpose of this work was to evaluate a programme designed to support pharmacists' transition to working in general practice settings. We explored the learning needs of pharmacists', the barriers and enablers to their integration and provide recommendations based on our results.

Intervention A qualitative evaluation of a 1-year transition programme in Wales starting in September 2018 to support pharmacists' transition to working in general practice settings.

Design and setting We employed an interpretative phenomenological approach involving 10 pharmacists across Wales enrolled on the transition to general practice training programme, and their tutors. Data were collected across two sequential phases: in phase 1 telephone interviews were held with pharmacists midway through their training; in phase 2, focus groups were conducted with both pharmacists and tutors towards the end of the programme. Results Pharmacists enter general practice settings with a variety of prior experience. The programme provided a framework that pharmacists found helpful to map their experience to but the programme needed to be flexible to individual learning needs. The tutor role was typically regarded as the most valuable component, but interaction with the wider general practice team was critical to ease the transition. Pharmacists encountered a lack of clarity about their role which impeded their integration into the workplace team.

Conclusions A formal programme with a designated tutor can support pharmacists' transition into general practice settings. The programme's competency framework facilitated reciprocal understanding of the pharmacist's role in the team, helped to manage expectations and enhanced collaborative practice. Recommendations to facilitate pharmacist integration into general practice settings are provided.

\section{INTRODUCTION}

Populations are ageing and the prevalence of chronic conditions increasing. Combined

\section{STRENGTH AND LIMITATIONS OF THIS STUDY}

$\Rightarrow$ The data, collected from multiple sources (tutees and tutors), at multiple time points is a strength of the study, permitting triangulation of views.

$\Rightarrow$ Results from phase 1 informed data collection in phase 2, therefore permitting additional follow-up and clarification of key points.

$\Rightarrow$ Although the study sample was Wales-wide, we acknowledge the small participant numbers.

$\Rightarrow$ The study would be strengthened by a longitudinal follow-up of tutees to explore the contributions of pharmacists to primary care teams.

$\Rightarrow$ Perceptions from other members of the general practice team, and patients, would provide a further and external viewpoint on the training programme and more generally, on the pharmacist role in primary care.

with shortfalls in recruitment of general practitioners (GPs) and practice nurses, it is challenging for general practice surgeries in the UK to meet the health demands of today's society, particularly within the context of a pandemic. ${ }^{12}$ To alleviate such pressures, the composition of interprofessional care teams is broadening within primary care health systems in the UK and further afield. ${ }^{34}$ This development has embraced pharmacists and resulted in substantial changes to their role which was traditionally based in either community or hospital settings. In the last decade, pharmacists have increasingly been integrated into the skill mix of general practice surgeries. ${ }^{4}$

The introduction of pharmacists to the general practice skill mix provides a valuable asset to patients and a complementary skill set to other primary healthcare professions. ${ }^{1}$ Specific benefits seen so far include a reduction in patient waiting time; improved screenings and diagnoses of chronic and common 
ailments; a reduction in medicine waste and savings in general practice locum costs. ${ }^{5}$ An observational study in Scotland revealed that the integration of a clinical pharmacist into a general practice released as much as 5 hours of GP time each week. ${ }^{6}$

However, it is not uncommon for pharmacists to be confronted with barriers to their integration. Lack of clarity on their role can result in other healthcare professionals in the team not knowing what to expect from the pharmacist. ${ }^{46}$ Furthermore, in the early integration phases, rather than alleviating pressures, the pharmacist's dependence on other team members can instead create additional work for physicians and nurses. ${ }^{7}$

Therefore, to support pharmacists transitioning into the general practice setting in Wales, Health Education and Improvement Wales (HEIW) devised a new training programme that offers tailored support to pharmacists taking up these roles. The transition programme runs over 12 months and is centred on a competency-based framework for general practice-based pharmacists as approved by the Royal Pharmaceutical Society (RPS) (see online supplemental material). Pharmacists undertake self-assessments against this competency framework at months 3, 6 and 12 of the programme, which are used to inform their training needs. Each pharmacist is provided with 21-days of one-to-one support from an experienced general practice pharmacist (having a minimum of 3 years' experience in a clinical patient-facing role and a practicing independent prescriber (IP)) who is trained as a tutor. In months 1-3, the pharmacists receive support on a day-a-week basis. This reduces to 1 day-a-fortnight in months $4-6$ and to half-a-day-a-month in months 7-12. The role of the tutor is to support the development of a workplan for the pharmacist, provide ongoing support throughout the programme, review the pharmacist's progress and all evidence they collect against the competency framework and sign-off competencies that have been sufficiently demonstrated.

In recruiting pharmacists onto the programme, HEIW targeted all pharmacists new to a general practice role by circulating programme information flyers to general practice surgeries in Wales. HEIW specified two entry requirements for enrolment: pharmacists had to be employed within a general practice surgery and hold less than 12 months of experience in their role. A total of 10 eligible pharmacists enrolled onto the training programme.

Given that the competency-based framework had previously been reviewed and approved by the RPS, the focus of this study was on training structure and support rather than curriculum and competencies. Our purpose was to evaluate the programme, focusing on the experiences of the pharmacists transiting to working in general practice settings and the views of their tutors. As our primary outcomes, we sought to address three research questions: 1. In the context of prior experience, what are the learning and support needs of the pharmacists joining the training programme?
2. What are pharmacists' and tutors' views and experience of the transition training programme?

3. What challenges do pharmacists face in transitioning into a general practice role?

\section{METHOD}

This study employed an interpretative phenomenological approach (IPA) in order to provide a detailed exploration of the transition training programme that reflects the participants' personal accounts and evaluations. ${ }^{8}$ Although there is a descriptive element, which was important in the context of sensitivity towards individual perceptions and responses from participants with varied experiences prior to entering the programme, IPA allows us to go beyond description and draw out commonalities and differences across participants. Our target participants were pharmacists on the transition programme and their tutors as our focus was primarily experiential: the learning and support needs of pharmacists and their experiences of transition and integration into GP practice settings. The nature of the tutor role meant that they were in close contact with these pharmacists and so offered a complementary perspective of the programme.

Ten pharmacists (referred to herein as tutees) were recruited by University Health Boards (UHBs) in Wales to enrol on the transition training programme: three in Betsi Cadwaladr, three in Cwm Taf Morgannwg, two in Aneurin Bevan and one each in Hywel Dda and in Swansea Bay. All 10 tutees and their tutors were invited to participate in the study. Invitations to participate in the study were drafted by the researchers and distributed via HEIW on their behalf. Data collection was undertaken in two phases between April and September 2019:

- Phase 1 (April-June): telephone interviews with tutees approximately midway through the transition training programme

- Phase 2 (September): focus groups with tutees and tutors towards the end of the transition training programme.

The change from interviews to focus groups in phase 2 was implemented in order to capitalise on participants' confirmed attendance at a prearranged event and thus minimising the impact and time the evaluation required from participants. This approach also provided a greater assurance that we would be able to capture data from all tutees on the programme. Interviews and focus groups were carried out by authors $\mathrm{SB}$ and $\mathrm{AB}$ who had no existing relationships with participants. They participated in a briefing prior to each round of data collection to ensure a common aim, understanding and approach. Interviews were semi-structured, and the study design involved a sequential approach to data collection such that data from phase 1 were coded, reviewed and used to inform the question schedules implemented in phase 2. All question schedules are provided in the online supplemental material. 
Table 1 Summary of data collection

\begin{tabular}{llllc}
\hline Phase of study & Data collection method & No. of tutees & No. of tutors & $\begin{array}{c}\text { Total no. of } \\
\text { participants }\end{array}$ \\
\hline Phase 1 & One-to-one telephone interviews & 10 & - & 10 \\
\hline Phase 2 & Focus group 1 & 3 & 2 & 5 \\
& Focus group 2 & 7 & 0 & 7 \\
& Focus group 3 & 0 & 4 & 4
\end{tabular}

Telephone interviews were held with tutees at a time suggested by them and focus groups took place at scheduled study days tutees and tutors were already attending. In total, three focus groups were conducted: one with tutees only, one with tutors only and one mixed. For logistical purposes, the mixed focus group was conducted via teleconference, and it was not possible to separate tutees and tutors due to access to video-conferencing at the venue. All telephone interviews and focus groups were audio recorded and transcribed verbatim. Transcriptions were checked for accuracy and transferred into NVivo software for analysis. The data were analysed thematically, following six steps: ${ }^{9}$ familiarisation with the data, generation of initial codes, identification of themes, theme review, defining and naming themes, reporting. Codes were initially generated by one author (SB) and then discussed and agreed with a second author (AB). Final themes were mapped against the research questions for reporting.

To protect identity, all participants were assigned a pseudonym and individual UHBs are not named in the results. Participant roles (tutee, tutor) and study phases are reported to provide context and reflect the evolution and longevity of views.

\section{Patient and public involvement}

No patient involved.

\section{RESULTS}

Across both phases, data were gathered from all 10 tutees, and six of the 10 tutors (see table 1). A total of 2 hours 50 min of interview data was gathered in phase 1 from the 10 participants (average of 17 min per interview). Focus groups in phase 2 yielded a total of 1 hour $21 \mathrm{~min}$ of conversation data (average of $27 \mathrm{~min}$ per focus group).

Tutees entered the programme with a range of prior experiences in pharmacy (see table 2): all bar one had some community pharmacy experience and five had some experience in a general practice setting. Many of the tutees had been qualified for more than ten years. Three were currently working across multiple general practices within a geographical area. In the presentation of findings, we draw attention to whether participants had prior experience in general practice settings.

Due to our engagement with all tutees on the programme and the evident variety in their prior experiences, we sought to explore individual personal experiences and therefore data saturation is not discussed. Data saturation is also a contested concept within qualitative research, particularly outside the use of grounded theory. ${ }^{10}$

Results are organised around key themes that have been mapped against our three research questions: learning and support needs of pharmacists, views and experiences

Table 2 Summary of tutees' experience in pharmacy sectors prior to the training programme

\begin{tabular}{|c|c|c|c|c|}
\hline Tutee (pseudonym) & Hospital experience & Community experience & General practice experience & Cluster pharmacist* \\
\hline Sarah & $x$ & $x$ & & \\
\hline Anna & & $x$ & & $x$ \\
\hline Melanie & & $X$ & $x$ & \\
\hline Alun & $x$ & $x$ & & $x$ \\
\hline George & & $X$ & $x$ & \\
\hline Glesni & $x$ & & $x$ & $x$ \\
\hline Suzie & & $x$ & $x$ & \\
\hline Steffan & $x$ & $x$ & & \\
\hline
\end{tabular}

${ }^{*}$ Cluster pharmacists are employed by the Health Board to work across a group of practices within a 'primary care cluster' rather than in one fixed practice. 
of the transition training programme and challenges for pharmacists in the general practice setting.

\section{Learning and support needs of pharmacists}

In phase 1, tutees were asked about their learning and development needs and what they hoped to gain from the transition training programme. Tutees with no prior experiences in general practice settings wanted a structured learning programme that provided a clear direction 'mapped out for you in advance' for a relatively new role:

I just think having a structure in place of what you need to cover $[\ldots]$ rather than just floundering along and dealing with things when you get to them. (Anna, Tutee, phase 1)

Several also wanted to know more about the particulars of the general practice environment and gain a 'a good idea of what is required' to develop their confidence in this setting. Tutees who already had some experience in general practice settings reported wanting to shift their focus more towards face-to-face patient interactions and so wanted to develop their consultation and clinical skills, particularly in working with patients with complex needs. Melanie described this shift in focus:

When I started in primary care (i.e. a general practice setting), it was as a prescribing advisor, going around a variety of surgeries and helping them with auditing and cost savings and safe prescribing and things like that. So not necessarily going into like the nitty gritty and face-to-face contact with the patients. (Melanie, Tutee, phase 1)

If prior work experience had been in a different sector, tutees wanted to understand how primary care 'works'. Tutees both with and without prior general practice experience, welcomed the opportunity to 'learn off other people' and gain input from experienced pharmacists 'who have done the role before'.

\section{Views and experiences of the transition training programme}

There were several key aspects of the training programme that participants commonly commented on. These were in relation to the tutor role, pharmacists' interactions with other healthcare professionals, how this transition training programme had influenced their practice and where they saw scope for improvements to the programme. Each of these is discussed in turn.

\section{Added value of tutor role}

Tutees emphasised the value of the tutor role. Many commented on this, describing the tutor as 'absolutely brilliant', 'the best thing' and 'most important' aspect of the programme. They emphasised that the tutor was a central component and noted that the programme 'isn't going to work on its own'. Alun, for example, ascribed his development to the tutor's input:
My mentor (tutor) has been very good and he's afforded me the opportunity to upskill very quickly. I wouldn't be in the position at this stage if it wasn't for the input from them. (Alun, Tutee, phase 1)

Specifically, tutees commented on how tutors both tailored the structured programme to tutees' learning needs and also reduced feelings of isolation. Given the diversity of pharmacists' roles, some tutees in phase 1 specifically commented on the need for a 'tailored' programme that could be 'flexible to who it's for'. Tutees recognised their different starting points and expressed concern that for those with more experience, competencies geared to pharmacists new to general practice could become a 'tick-box exercise'. For example, Glesni, with prior experience of working in a general practice, commented:

Some of the competencies you've done but you haven't actually got the evidence for them. So is it a bit time consuming and a lot of work just to add them.

(Glesni, Tutee, phase 1)

However, as they progressed through the programme, it appeared that tutors were able to respond flexibly and that together, the tutee and tutor could tailor the framework to suit individual needs. One tutor explained:

She (tutee) already knew the basics of the practice and what to do with the practice. She didn't need that front-loading. But if you had someone who was new into the role and never done it, obviously you'd need to schedule a lot more time initially either with the tutor or with other members of the team to make sure that they get the good support and the good grounding with how practices work. (Emma, Tutor, phase 2)

One tutee described a negotiated approach, commenting that 'it's almost an agreement between you and your tutor.... It's whatever works for you really'. (Alun, Tutee, phase 2)

Tutors also helped to reduce feelings of isolation often experienced in pharmacy settings ${ }^{11} 12$ and offered a 'buddy system' of support. Although Harry had prior experience of working in a general practice setting, he recognised the isolation issue: 'I think as pharmacists it's very easy to get isolated and put on your own', and highlighted the value of the tutor: 'So, to be put with a tutor where you can link in with somebody, you can run things by and question, is really useful'. (Harry, Tutee, phase 2)

The tutor as a sounding board was emphasised by others. Steffan (Tutee, phase 1) remarked how it had been 'really good to have somebody at the end of the phone [...] or send a text, just to ask questions'. . In addition to informal contact, both tutors and tutees stressed the importance of scheduling regular meetings, ensuring that this was protected time to focus on the tutee's development:

Making sure that time is actually set aside to spend with your tutee, rather than just trying to do it in amongst everything else. I think having that one-to-one time 
when you're only focussing on the course, is really important. (Anna, Tutee, phase 2)

\section{Interactions with other healthcare professionals}

Despite their critical role, tutors also felt it was important that tutees interacted with other clinicians in the workplace team and were not solely reliant on their tutor's expertise:

From the tutor's perspective you've got enough flexibility for the students (tutees) to be able to do stuff with you but also with other people, so that they can get a lot of experience with the clinicians, different people that we also work with, different people in the team to gain their competencies for the different requirements. (Emma, Tutor, phase 2)

This was echoed by the tutees who generally spoke positively about the support they had received from GPs, nurses and in some cases, other pharmacists. Alun, who had no prior experience in general practice settings commented:

One of the GPs says, 'actually that was good, but you could have done this, you could have considered that.' And so, I'm getting support there. The nurses are the ones I tend to interact with, I've got good working relationships with most of them. (Alun, Tutee, phase 1)

Tutors commented on the value of clear expectations of pharmacists on this programme. In their view, this strengthened tutees' relationships within the practices. In terms of offering advice to prospective tutees and tutors, both groups commented on the importance of 'build(ing) up the connections between tutors and other people in the practice as early as you can, so you can understand better how everyone works' (George, Tutee, phase 2). Fiona, a tutor, also argued for 'liaison between the tutor and their line manager'.

\section{Influence on practice}

While in phase 1 , tutees reported a desire to build their confidence, phase 2 provided evidence that this had been achieved and tutees, both with and without prior general practice experience, had become more aware of their strengths and scope of practice:

It's almost an evaluation of how you're doing: what you need to improve on and what you're doing great ... It also gives you a bit of confidence that you can do the job and you're fully aware of what is expected of you. (Jessica, Tutee, phase 1)

It's given me a bit of confidence... as the year has gone by it makes me think 'actually, I do know what I'm doing'...I suppose when you're doing the work day-to-day because you're not documenting what you've done you don't realise the scope of your practice. (Melanie, Tutee, phase 2)
One tutee with experience in general practice settings felt that the requirement to reflect on and justify decisions during their training had helped him to practice more safely:

It certainly makes you reflect on the way you practice and think about safety boundaries. I think that's worth the training course just even to do that and we can justify any decisions you make while you're practising. This programme has made me think about that. (Harry, Tutee, phase 2)

\section{Areas for programme improvement}

Tutees generally reflected positively on the transition training programme, citing it as 'extremely beneficial' and a 'really good opportunity':

I think the content is ideal really. It covers literally everything you need to know to prepare you to do the job. (Sarah, Tutee, phase 2)

Similarly, tutors felt the programme was 'really positive' and 'hugely valuable'. Both groups reported that they would advise any pharmacist intending to move into the general practice setting to pursue the programme. That said, tutees and tutors were forthcoming in suggesting improvements to the programme. Several tutees reported a desire for greater clarity or direction in evidencing competencies:

I'm used to the concept of gathering evidence to prove competence, but I think it was a little bit confusing really of exactly what evidence you needed. (Sarah, Tutee, phase 1)

A further area of improvement related to a more deliberate matching of tutors and tutees in terms of geography, work rotas and computer systems. It was suggested that this would help tutees to get the most out of their interaction with their tutors.

\section{Challenges for pharmacists in the general practice setting}

Participants discussed broader challenges to their integration into the general practice setting. There was discussion about the lack of awareness of the pharmacist's role in such a setting. Alun (Tutee, phase 1) remarked: 'I thought it would be a very clearly defined role and actually it wasn't'. Lack of a shared understanding of the pharmacist's role stood as a potential barrier to their training, development and integration:

A lot of employers who had never had pharmacists before don't really know what we can and can't do. (Harry, Tutee, phase 1)

Tutees felt that this awareness needed to be reciprocal so that employers know what to expect from pharmacists and pharmacists know what is expected of them, and when to say no if asked to do something beyond their scope of practice. However, concerns were not unanimous, and levels of role clarity appeared to vary across practices: 
The practice where I am now, have got a really good awareness of pharmacists and what we do. I think both practices had pharmacists for a number of years, so they're quite experienced in terms of knowing what we bring to the role really. (Steffan, Tutee, phase 1)

Tutors also underscored the importance of employers both understanding the pharmacist role and also recognising their commitments while on the programme. Tutees highlighted difficulties more related to the training programme itself. These related to the cluster pharmacists experiencing different computer systems across practices or inconsistency in computer systems across tutor and tutee practices. The logistics of working across multiple practices also presented challenges for both the tutees and tutors:

I'm just doing different things every day in different surgeries, and from that perspective it's been slightly harder to plan my training time. (Anna, Tutee, phase 1)

Having a set structured day would be much more helpful but she couldn't do that because of pressure on her from the practices. (Fiona, Tutor, phase 2)

Some tutees were pursuing the IP course in parallel to the transition training programme. However, doing both in parallel raised prioritisation issues; in some cases, portfolio development was stalled while the prescribing course was prioritised. Tutors were aware of such problems, sensing their tutees were 'overwhelmed by doing the two together' and the general consensus among tutors was that they would not recommend that the IP course is undertaken at the same time as the transition programme. Some suggested that the pursuit of the IP course could be viewed as an appropriate next step and one tutee specifically remarked that it 'would be good if it (the transition training) leads onto that'.

\section{DISCUSSION}

This study yielded a rich understanding of tutees' and tutors' experience of the transition training programme in Wales. Given that many pharmacists entering general practice settings will have a range of prior experience and varied backgrounds, our results indicate the importance of having a transition programme flexible enough to tailor to different learning needs. The role of the tutor is critical in ensuring this tailored learning approach and the tutee-tutor relationship can also help to alleviate feelings of isolation. The importance of relationships with the wider general practice team is also emphasised. The competency framework embedded within the training programme can facilitate role clarity among stakeholders and assist the management of expectations.

Researchers $\mathrm{SB}$ and $\mathrm{AB}$ undertook the data collection and analysis. Their impartial position as social scientists, not influenced by working within the healthcare sector, lessened the risk of biased interpretation of the data collected. This had the disadvantage of limited contextual knowledge, but this was addressed through consultation with pharmacy education leads at HEIW and coauthor, and general practice pharmacist, KS. Furthermore, results from phase 1 informed data collection in phase 2 which permitted additional follow-up and clarification of key points. Although data interpretations were not directly confirmed with participants, results were discussed with pharmacy education leads at HEIW. In terms of sample size, although Wales-wide, we acknowledge that participant numbers were small and that specifically, those who took part in the mixed focus group (comprising both tutors and tutees) may have been less candid in their responses, although there was no evidence of this in comparison to the data collected from single role groups. We also recognise the limitation of a Wales-only study but suggest that our recommendations are relevant to wider interprofessional general practice teams.

The importance yet lack of role clarity and understanding of pharmacists' scope of practice is by no means a new finding. There have been reports of occasions in practice where pharmacists felt GPs' expectations were too high and unsustainable given time constraints. ${ }^{6}$ It has been argued that this barrier can be overcome when the pharmacist works with the general practice team to develop a job description. ${ }^{3}{ }^{4}$ Other research suggests the need for regular meetings between pharmacists and other practice staff $\mathrm{f}^{13}$ and ongoing stakeholder consultation. ${ }^{14}$ However, we argue that a widely implemented competency framework could provide a valuable resource that pharmacists and the wider team can refer to from the outset and could be used to manage expectations. Nonetheless, we recognise there is not a 'one-size-fits-all' and consideration should also be given to the needs of the individual general practice, and not merely assuming a rigid national role description. ${ }^{15}$

The matter of role clarity also draws on the importance of interprofessional collaboration, endorsed by the General Medical Council (GMC) in 'Good Medical Practice' where it is stated that doctors practicing in the UK 'must work collaboratively with colleagues, respecting their skills and contributions'. ${ }^{16}$ Effective teamwork is recognised as key to the delivery of safe patient care and poor collaboration puts patients at greater risk of harm. ${ }^{17} 18$

Where this study has demonstrated that pharmacists' professional relationships with the general practice team were paramount to successful integration, elsewhere, we see that such relationships are facilitated by open communication, respecting the expertise of different team members and by pharmacists exhibiting an approachable demeanour to the wider team. ${ }^{4}$ Although a framework, such as that utilised in the transition programme, could aid interprofessional collaboration within the general practice team, it cannot guarantee mutual respect for skills and contribution to activity in general practice. The role of the tutor appears to be critical to pharmacists' transition, not only ensuring training is tailored 
Table 3 Recommendations

\begin{tabular}{|c|c|}
\hline Professional role & Suggestions \\
\hline $\begin{array}{l}\text { Pharmacists considering } \\
\text { transitioning into general } \\
\text { practice teams }\end{array}$ & $\begin{array}{l}\text { The competency framework for the pharmacists' role, provided by the transition training } \\
\text { programme should be used to manage expectations } \\
\text { A formal tutor is integral to tutee development, but pharmacists should also establish good } \\
\text { relationships with the general practice healthcare team }\end{array}$ \\
\hline $\begin{array}{l}\text { General Practice } \\
\text { Professionals }\end{array}$ & $\begin{array}{l}\text { The wider general practice team should use a standardised competency framework to facilitate } \\
\text { their understanding of the pharmacist role and their scope of practice } \\
\text { The general practice team should aim to build a relationship with the pharmacist (and their } \\
\text { tutor), to share expectations and enhance integration }\end{array}$ \\
\hline Educators and tutors & $\begin{array}{l}\text { Pharmacists will enter general practice settings with various learning and development needs. A } \\
\text { transition programme must be flexible enough to be tailored to these } \\
\text { The IP course would be a well-positioned follow-on from the transition programme, but pursuing } \\
\text { this in parallel to the transition training is not recommended } \\
\text { Cluster pharmacists can face difficulties in time management across multiple practices; this } \\
\text { needs to be considered in any transition programme } \\
\text { Learning is supported where tutees and tutors are appropriately matched (in terms of } \\
\text { geography, work rotas and practice computer systems) }\end{array}$ \\
\hline
\end{tabular}

to need, where we note that some pharmacists may not recognise gaps in their knowledge and skillset, ${ }^{19}$ but also in supporting the pharmacist to forge relationships with other general practice team members. In turn, this facilitates the general practice team working collectively in the best interests and safety of their patients.

The suggestion of the IP course becoming a natural follow-on from the transition programme is worthy of consideration given that it appears to be a common intention of these pharmacists and will impact on the role they can fulfil in primary care. Elsewhere, prescribing pharmacists have been seen directly to save a GP appointment for acute illnesses, ${ }^{1}$ and pharmacists who were already IPs or completing the course have displayed higher self-assessed competence in their day-to-day general practice role than those without. ${ }^{20}$

In terms of further research, we suggest that a longitudinal follow-up of tutees could valuably explore the contribution of pharmacists to primary care teams. Such longer-term follow-up could also seek reflections on the competencies, identifying those particularly relevant to the role, irrelevant or missing. The focus of this study was to understand the pharmacists' perspective on their learning and support needs and experience of integration, and to triangulate their views with the tutors. This added to the validity of the otherwise one-sided tutee perspective. In future research, additional perceptions from other members of the general practice team, and patients, would provide a further viewpoint on the training programme and more generally, on the pharmacist role in primary care.

A programme such as this could smooth pharmacists' transition into the general practice setting, both by supplying essential tutor support and also by providing a framework for pharmacists and other staff in the general practice team to enhance their understanding of the pharmacists' scope of practice and encourage interprofessional collaboration. In conclusion, points for consideration by stakeholders (pharmacists, general practice professionals and educators supporting this transition) are suggested in table 3 . These are focused on how to support pharmacists integrating into general practice settings.

\section{Twitter Alison Bullock @CUREMeDE}

Acknowledgements We would like to acknowledge Health Education and Improvement Wales (HEIW) for commissioning and funding this study. We are most grateful to all the trainees and tutors on the transition training programme who kindly gave up their time and consented to be interviewed or take part in a focus group for this study.

Contributors $S B$ is responsible for the overall content of this article as the guarantor. $A B$ was the study lead overseeing all activity. $S B$ and $A B$ designed the study protocol and data collection instruments and obtained ethics approval. KS coordinated participant recruitment, SB and AB performed data collection. Data analysis was initially undertaken by SB and themes were discussed, checked and reviewed with $A B$. SB produced the first paper draft and $A B$ and $K S$ contributed to revisions. All authors have given their approval of this version to be published and all have agreed to be accountable for all aspects of the work including matters related to accuracy or integrity.

Funding This work was supported by the Pharmacy division of Health Education and Improvement Wales. Award/grant number not applicable.

Competing interests Coauthor KS, in her role at Health Education and Improvement Wales, was associated with the implementation of the transition training programme. However, the data collection and analysis were undertaken by the other authors ( $\mathrm{SB}$ and $\mathrm{AB}$ ).

Patient consent for publication Consent obtained directly from patient(s).

Ethics approval This study was granted ethics approval from the School of Social Sciences Research Ethics Committee at Cardiff University (SREC/3082).

Provenance and peer review Not commissioned; externally peer reviewed.

Data availability statement № data are available. No data are available. We gained ethics approval on the premise that no data would be shared outside the core research team.

Supplemental material This content has been supplied by the author(s). It has not been vetted by BMJ Publishing Group Limited (BMJ) and may not have been peer-reviewed. Any opinions or recommendations discussed are solely those 
of the author(s) and are not endorsed by BMJ. BMJ disclaims all liability and responsibility arising from any reliance placed on the content. Where the content includes any translated material, BMJ does not warrant the accuracy and reliability of the translations (including but not limited to local regulations, clinical guidelines, terminology, drug names and drug dosages), and is not responsible for any error and/or omissions arising from translation and adaptation or otherwise.

Open access This is an open access article distributed in accordance with the Creative Commons Attribution Non Commercial (CC BY-NC 4.0) license, which permits others to distribute, remix, adapt, build upon this work non-commercially, and license their derivative works on different terms, provided the original work is properly cited, appropriate credit is given, any changes made indicated, and the use is non-commercial. See: http://creativecommons.org/licenses/by-nc/4.0/.

\section{ORCID iD}

Sophie Bartlett http://orcid.org/0000-0001-6958-0910

\section{REFERENCES}

1 Stone MC, Williams HC. Clinical pharmacists in general practice: value for patients and the practice of a new role. Br J Gen Pract 2015;65:262-3.

2 Smith J, Holder H, Edwards N. Securing the Future of General Practice: new models of primary care: Research Report [Internet]. Nuffield Trust and King's Fund, 2013. Available: https://www. nuffieldtrust.org.uk/research/securing-the-future-of-general-practicenew-models-of-primary-care [Accessed 06 Sep 2021].

3 Jorgenson D, Laubscher T, Lyons B, et al. Integrating pharmacists into primary care teams: barriers and facilitators. Int J Pharm Pract 2014;22:292-9.

4 Jorgenson D, Dalton D, Farrell B, et al. Guidelines for pharmacists integrating into primary care teams. Can Pharm J 2013;146:342-52.

5 The British Medical Association. Employing clinical pharmacists in GP practices [Internet] The British Medical Association, 2020. Available: https://www.bma.org.uk/advice-and-support/gp-practices/ employment-advice/employing-clinical-pharmacists-in-gp-practices [Accessed 06 Sep 2021].

6 Maskrey M, Johnson CF, Cormack J, et al. Releasing GP capacity with pharmacy prescribing support and new ways of working: a prospective observational cohort study. $\mathrm{Br} J$ Gen Pract 2018;68:e735-42.
7 Brock KA, Doucette WR. Collaborative working relationships between pharmacists and physicians: an exploratory study. J Am Pharm Assoc 2004;44:358-65.

8 Smith JA, Osborn M. Interpretative Phenomenological Analysis. In: Smith JA, ed. Qualitative psychology: a practical guide to research methods. Sage Publications, 2003: 51-80.

9 Braun V, Clarke V. Using thematic analysis in psychology. Qual Res Psychol 2006;3:77-101.

10 O’Reilly M, Parker N. 'Unsatisfactory Saturation': a critical exploration of the notion of saturated sample sizes in qualitative research. Qual Res 2013;13:190-7.

11 Astbury JL, Gallagher CT. Moral distress among community pharmacists: causes and achievable remedies. Res Social Adm Pharm 2020;16:321-8.

12 Cooper RJ, Bissell P, Wingfield J. 'Islands' and 'doctor's tool': the ethical significance of isolation and subordination in UK community pharmacy. Health 2009;13:297-316.

13 Ryan K, Patel N, Lau WM, et al. Pharmacists in general practice: a qualitative interview case study of stakeholders' experiences in a West London GP Federation. BMC Health Serv Res 2018;18:234

14 Tan ECK, Stewart K, Elliott RA, et al. Integration of pharmacists into general practice clinics in Australia: the views of general practitioners and pharmacists. Int J Pharm Pract 2014;22:28-37.

15 Anderson C, Zhan K, Boyd M, et al. The role of pharmacists in general practice: a realist review. Res Social Adm Pharm 2019;15:338-45.

16 General Medical Council. Good Medical Practice [Internet]. General Medical Council, 2013. Available: https://www.gmc-uk.org/ethicalguidance/ethical-guidance-for-doctors/good-medical-practice [Accessed 06 Sep 2021].

17 Leonard M, Graham S, Bonacum D. The human factor: the critical importance of effective teamwork and communication in providing safe care. Qual Saf Health Care 2004;13 Suppl 1:85-90.

18 Green B, Oeppen RS, Smith DW, et al. Challenging hierarchy in healthcare teams - ways to flatten gradients to improve teamwork and patient care. Br J Oral Maxillofac Surg 2017;55:449-53.

19 Butterworth J, Sansom A, Sims L, et al. Pharmacists' perceptions of their emerging general practice roles in UK primary care: a qualitative interview study. Br J Gen Pract 2017;67:e650-8.

20 Matheson C, Reid F, Stewart F, et al. Development of an education and support framework for pharmacists working in GP practice. Int $J$ Pharm Pract 2020;28:191-9. 